\title{
Numerical Solutions of a Class of Nonlinear Volterra Integral Equations
}

\author{
H. S. Malindzisa and M. Khumalo \\ Department of Pure and Applied Mathematics, University of Johannesburg, P.O. Box 524, Auckland Park 2006, South Africa \\ Correspondence should be addressed to H. S. Malindzisa; hlukaphi@gmail.com
}

Received 10 April 2014; Revised 17 June 2014; Accepted 26 June 2014; Published 9 July 2014

Academic Editor: Chun-Gang Zhu

Copyright ( $) 2014$ H. S. Malindzisa and M. Khumalo. This is an open access article distributed under the Creative Commons Attribution License, which permits unrestricted use, distribution, and reproduction in any medium, provided the original work is properly cited.

\begin{abstract}
We consider numerical solutions of a class of nonlinear (nonstandard) Volterra integral equations. We first prove the existence and uniqueness of the solution of the Volterra integral equation in the context of the space of continuous functions over a closed interval. We then use one-point collocation methods with a uniform mesh to construct solutions of the nonlinear (nonstandard) VIE and quadrature rules. We conclude that the repeated Simpson's rule gives better solutions when a reasonably large value of the stepsize is used.
\end{abstract}

\section{Introduction}

In this paper we study the nonlinear (nonstandard) Volterra integral equation of the second kind of the form

$$
u(t)=\sum_{j=1}^{r} b_{j}\left(g_{j}(t)+\int_{0}^{t} k_{j}(t, s) u(s) d s\right)^{j}, \quad t \in[0, T],
$$

where $(r \in \mathbb{N}, r \geq 2)$, with $b_{j} \in \mathbb{R}$, and $g_{j}, k_{j}$ are continuous functions. Volterra integral equations play an important part in scientific and engineering problems such as population dynamics, spread of epidemics, semiconductor devices, wave propagation, superfluidity, and travelling wave analysis, Saveljeva [1]. In cases where the kernel is of convolution type $(K(t, s)=K(t-s))$ the solutions to (1) include elliptic functions and natural generalizations of these functions which also have wide applications in the fields of science and engineering [2]. This class of Volterra integral equations was considered by Sloss and Blyth [2] who proved the existence and uniqueness of the solution in the Banach space $L^{2}$ and applied the Corrington's Walsh function method to $(1)$.

Much work has been done in the study of numerical solutions to Volterra integral equations using collocation methods [1,3-7]. Benitez and Bolos [8] pointed out that collocation methods have proven to be a very suitable technique for approximating solutions to nonlinear integral equations because of their stability and accuracy. Other authors such as [9-12] used quadrature rules like repeated trapezoidal and repeated Simpson's rule to solve linear Volterra integral equations. However, collocation methods and quadrature rules have not been used to approximate solutions to (1).

\section{The Numerical Methods}

2.1. The Collocation Method. In our work we focus on onepoint collocation methods (see [13]).

Let $t_{n}:=n h(n=0,1, \ldots, N-1)$ define a uniform partition for $I=[0, T]$ and set $Z_{N}:=t_{0}, \ldots, t_{N}, I_{0}:=$ $\left[t_{0}, t_{1}\right] I_{n}:=\left(t_{n}, t_{n+1}\right](1 \leq n \leq N-1)$. The solution to (1) will be approximated by using collocation in the piecewise constant polynomial space $S_{0}^{-1}\left(Z_{N}\right)$.

For a given real number $c_{1}$, define the set $X_{N}:=t_{n, 1}$ of collocation points by

$$
t_{n, 1}=t_{n}+c_{1} h \quad\left(0 \leq c_{1} \leq 1, n=0, \ldots, N-1\right) .
$$

The collocation solution $u_{n} \in S_{0}^{-1}\left(Z_{N}\right)$ is defined by the collocation equation

$$
u_{n}(t)=\sum_{j=1}^{r} b_{j}\left(g_{j}(t)+\int_{0}^{t} k_{j}(t, s) u(s) d s\right)^{j}, \quad t \in X_{N},
$$


since

$$
u_{n}(t)=u_{n}\left(t_{n}+v h\right)=L_{1}(\nu) U_{n, 1}, \quad \nu \in(0,1],
$$

where $L_{1}(\nu)=1$ and is a Lagrange fundamental polynomial.

Thus for $t=t_{n, 1}:=t_{n}+c_{1} h$ and $0<c_{1} \leq 1$ the collocation equation (3) assumes the form

$$
\begin{aligned}
u_{n}(t)=\sum_{j=1}^{r} b_{j}\left(g_{j}(t)+\int_{0}^{t_{n}} k_{j}(t, s) u_{i}(s)\right. \\
\left.+h \int_{0}^{c_{1}} k_{j}\left(t, t_{n}+s h\right) u_{n}\left(t_{n}+s h\right) d s\right)^{j} .
\end{aligned}
$$

Expressing the collocation equation in terms of the stage values we get

$$
\begin{aligned}
U_{n, 1}=\sum_{j=1}^{r} b_{j}( & g_{j}\left(t_{n, 1}\right)+F_{j n}\left(t_{n, 1}\right) \\
& \left.+h\left(\int_{0}^{c_{1}} k_{j}\left(t_{n, 1}, t_{n}+s h\right) d s\right) U_{n, 1}\right)^{j} .
\end{aligned}
$$

Let $t \in I_{n}$ and define

$$
F_{j n}(t):=\int_{0}^{t_{n}} k_{j}(t, s) u_{i}(s) d s .
$$

Then

$$
F_{j n}\left(t_{n, 1}\right)=h \sum_{i=0}^{n-1}\left(\int_{0}^{1} k_{j}\left(t_{n, 1}, t_{i}+s h\right) d s\right) U_{i, 1}
$$

The term $F_{j n}\left(t_{n, 1}\right)$ is called the lag term corresponding to the collocation solution, [13].

Iterated Collocation. The iterated approximation $u^{I}$ corresponding to $u$ is defined by

$$
u^{I}(t)=\sum_{j=1}^{r} b_{j}\left(g_{j}(t)+\int_{0}^{t} k_{j}(t, s) u(s) d s\right)^{j} t \in I
$$

(see $[4,5,14])$.

Set $t=t_{n} \in \overline{Z_{N}}$ and use (4); we may write (9) in the form

$$
u^{I}\left(t_{n}\right)=\sum_{j=1}^{r} b_{j}\left(g_{j}\left(t_{n}\right)+h \sum_{i=0}^{n-1} \int_{0}^{1} k_{j}\left(t_{n}, t_{i}+s h\right) d s U_{i, 1}\right)^{j} .
$$

2.2. Repeated Trapezoidal Rule. Using the trapezoidal rule we construct the solution to the integral equation (1) (see [12]). Let

$$
\begin{gathered}
t_{0}=a, \quad t_{n}=b \\
t_{i}=t_{0}+i h \quad i=0,1,2, \ldots, n \\
u\left(t_{i}\right)=\sum_{j=1}^{r} b_{j}\left(g_{j}\left(t_{i}\right)+\sum_{l=1}^{i} \int_{t_{l-1}}^{t_{i}} k_{j}\left(t_{i}, s\right) u(s) d s\right)^{j} \\
i=1,2, \ldots, n .
\end{gathered}
$$

The approximation of the integral in (11) by repeated trapezoidal rule will give the following system:

$$
u\left(t_{0}\right)=\sum_{j=1}^{r} b_{j}\left(g_{j}\right)^{j}
$$

$$
u\left(t_{1}\right)=\sum_{j=1}^{r} b_{j}\left(g_{j}\left(t_{1}\right)\right.
$$

$$
\left.+\frac{h}{2}\left(k_{j}\left(t_{1}, t_{0}\right) u\left(t_{0}\right)+k_{j}\left(t_{1}, t_{1}\right) u\left(t_{1}\right)\right)\right)^{j},
$$

$$
u\left(t_{2}\right)=\sum_{j=1}^{r} b_{j}\left(g_{j}\left(t_{2}\right)+\frac{h}{2} k_{j}\left(t_{2}, t_{0}\right) u\left(t_{0}\right)\right.
$$

$$
\left.+h k_{j}\left(t_{2}, t_{1}\right) u\left(t_{1}\right)+\frac{h}{2} k_{j}\left(t_{2}, t_{2}\right) u\left(t_{2}\right)\right)^{j},
$$

$$
u_{3}=\sum_{j=1}^{r} b_{j}\left(g_{j}\left(t_{3}\right)+\frac{h}{2} k_{j}\left(t_{3}, t_{0}\right) u\left(t_{0}\right)\right.
$$

$$
+h\left(k_{j}\left(t_{3}, t_{1}\right) u\left(t_{1}\right)\right.
$$$$
\left.+k_{j}\left(t_{3}, t_{2}\right) u\left(t_{2}\right)\right)
$$

$$
\left.+\frac{h}{2} k_{j}\left(t_{3}, t_{3}\right) u\left(t_{3}\right)\right)^{j}
$$

$$
\begin{aligned}
u\left(t_{n}\right)=\sum_{j=1}^{r} b_{j}\left(g_{j}\left(t_{n}\right)+\frac{h}{2} k_{j}\left(t_{n}, t_{0}\right) u\left(t_{0}\right)\right. \\
+h k_{j}\left(t_{n}, t_{1}\right) u\left(t_{1}\right)+\cdots+h k_{j}\left(t_{n}, t_{n-1}\right) \\
\left.\times u\left(t_{n-1}\right)+\frac{h}{2} k_{j}\left(t_{n}, t_{n}\right) u\left(t_{n}\right)\right)^{j}
\end{aligned}
$$

2.3. Repeated Simpson's Rule. We use repeated Simpson's rule to construct the solution to the integral equation (1) (see [9]).

If $n$ is even, then Simpson's rule may be applied to each subinterval $\left[t_{2 i}, t_{2 i+1}, t_{2 i+2}\right]$. For $i=0,1, \ldots,(N / 2)-1$ we have

$$
\int_{t_{2 i}}^{t_{2 i+2}} f(t) d s \simeq \frac{h}{3}\left[f\left(t_{2 i}\right)+4 f\left(t_{2 i+1}\right)+f\left(t_{2 i+2}\right)\right] .
$$

Summing up,

$$
\int_{a}^{b} f(t) d t=\frac{h}{3} \sum_{l=0}^{N-1}\left[f\left(t_{2 i}\right)+4 f\left(\frac{t_{2 l}+t_{2 l+2}}{2}\right)+f\left(t_{2 l+2}\right)\right] .
$$

We use (14) to solve the nonlinear (nonstandard) VIE. The approximation of (1) in the even nodes $t_{2 m}$ is given by

$$
u_{2 m}=\sum_{j=1}^{r} b_{j}\left[g_{j}\left(t_{2 m}\right)+\int_{a}^{t_{2 m}} k_{j}\left(t_{2 m}, s\right) u(s) d s\right]^{j} .
$$


Using

$$
u\left(t_{2 l+1}\right) \simeq \frac{u\left(t_{2 l}\right)+u\left(t_{2 l+2}\right)}{2}
$$

we obtain

$$
\begin{aligned}
& u\left(t_{2 m}\right)=\sum_{j=1}^{r} b_{j}\left[g_{j}\left(t_{2 m}\right)+\frac{h}{3} \sum_{l=0}^{m-1} k_{j}\left(t_{2 m}, t_{2 l}\right) u\left(t_{2 l}\right)\right. \\
& +4 k_{j}\left(t_{2 m}, t_{2 l+1}\right) \frac{u\left(t_{2 l}\right)+u\left(t_{2 l+2}\right)}{2} \\
& \left.+k_{j}\left(t_{2 m}, t_{2 l+2}\right) u\left(t_{2 l+2}\right)\right]^{j} \\
& u\left(t_{2 m}\right)=\sum_{j=1}^{r} b_{j}\left[g_{j}\left(t_{2 m}\right)\right. \\
& +\frac{h}{3} \sum_{l=0}^{m-1}\left(k_{j}\left(t_{2 m}, t_{2 l}\right)+2 k_{j}\left(t_{2 m}, t_{2 l+1}\right)\right) u\left(t_{2 l}\right) \\
& +\left(k_{j}\left(t_{2 m}, t_{2 l+1}\right)+2 k_{j}\left(t_{2 m}, t_{l+1}\right)\right) \\
& \left.\times u\left(t_{2 l+2}\right)\right]^{j} \\
& u\left(t_{2 m}\right)=\sum_{j=1}^{r} b_{j}\left[g_{j}\left(t_{2 m}\right)+\frac{h}{3}\left(k_{j}\left(t_{2 m}, t_{0}\right)+2 k_{j}\left(t_{2 m}, t_{1}\right)\right)\right. \\
& +\frac{h}{3}\left(k_{j}\left(t_{2 m}, t_{2 m}\right)+k_{j}\left(t_{2 m}, t_{2 m-1}\right)\right) u\left(t_{2 m}\right) \\
& +\frac{2 h}{3} \sum_{l=0}^{m-1}\left(k_{j}\left(t_{2 m}, t_{2 l-1}\right)+k_{j}\left(t_{2 m}, t_{2 l}\right)\right. \\
& \left.\left.+k_{j}\left(t_{2 m}, t_{2 l+1}\right)\right) u\left(t_{2 l}\right)\right]^{j} \text {. }
\end{aligned}
$$

\section{Existence and Uniqueness of the Solution}

The following theorem shows that when $r=2$ and $b_{1}=0$ the integral equation (1) has a unique solution in the space $C[0, d]$. Theorem 2 gives sufficient conditions for the solution to (1) to exist. We prove the existence and uniqueness of the solution using a procedure analogous to the one used in Sloss and Blyth [2].

\section{Theorem 1. The integral equation}

$$
z(t)=b\left(g(t)+\int_{0}^{t} k(t, s) z(s) d s\right)^{2}
$$

with $g \in C[0,1], b \in \mathbb{R}$, and $k(t, s) \in C([0,1] \times[0,1])$, has a unique solution $u$ and the solution belongs to $I_{d}=[0, d]$, $0<d \leq 1$, with

$$
0<d<\frac{1}{K}\left[\frac{1}{2 K|b|}-\|g\|_{\infty}\right]-\|u\|_{\infty}
$$

where

$$
K=\sup [0,1] \times[0,1]|k(t, s)| .
$$

Proof. The existence of the solution is shown in the corollary of Theorem 2 (in the next section). Here we prove the uniqueness of the solution. Let $u$ and $u+v$ be solutions of (18).

Then,

$$
\begin{aligned}
v(t)=b\left[g(t) \int_{0}^{t} k(t, s) v(s) d s\right. & \\
& +2 \int_{0}^{t} k(t, s) u(s) d s \cdot \int_{0}^{t} k(t, s) v(s) \\
& \left.+\left(\int_{0}^{t} k(t, s) v(s) d s\right)^{2}\right] .
\end{aligned}
$$

Define $T_{n}: C[0,1] \times C[0,1]$ by

$$
\begin{aligned}
T_{n} z(t)=\chi_{n} b\left[2 g(t) \int_{0}^{t} k(t, s) z(s) d s\right. \\
+2 \int_{0}^{t} k(t, s) u(s) d s \cdot \int_{0}^{t} k(t, s) z(s) d s \\
\left.+\left(\int_{0}^{t} k(t, s) z(s) d s\right)^{2}\right],
\end{aligned}
$$

where $\chi_{n}$ is a sequence of characteristic functions of intervals $\left[0, A_{n}\right] \subset[0,1]$.

Let $v_{1}+v_{2} \in C[0,1]$; consider

$$
\begin{aligned}
& T_{n} v_{1}(t)-T_{n} v_{2}(t) \\
& =\chi_{n}(t) b\left[2 g(t)+2 \int_{0}^{t} k(t, s) u(s) d s\right. \\
& \left.\quad+\int_{0}^{t} k(t, s)\left(v_{1}(s)+v_{2}(s)\right) d s\right] \\
& \quad \cdot \int_{0}^{t} k(t, s)\left(v_{1}(s)-v_{2}(s)\right) d s \\
& \stackrel{\text { def }}{=} b z\left(u, v_{1}, v_{2}\right)(t) \int_{0}^{t} k(t, s)\left(v_{1}(s)-v_{2}(s)\right) d s ;
\end{aligned}
$$

then,

$$
\begin{aligned}
& \left\|T_{n} v_{1}(t)-T_{n} v_{2}(t)\right\|_{\infty} \\
& \quad \leq\left\|b z \int_{0}^{1} K(t, s)\left(v_{1}(s)-v_{2}(s)\right) d s\right\|_{\infty} .
\end{aligned}
$$



$[0,1]$.

Let $d=\max _{0 \leq t \leq 1}\left(\left|v_{1}(t)\right|,\left|v_{2}(t)\right|\right)$ and take $T_{n}:[0, d] \rightarrow$ Then,

$$
\|z\|_{\infty} \leq 2\|g\|_{\infty}+2 K\|u\|_{\infty}+2 K d
$$

therefore

$$
\begin{aligned}
& \left\|T_{n} v_{1}(t)-T_{n} v_{2}(t)\right\|_{\infty} \\
& \quad \leq|b|\left(2\|g\|_{\infty}+2 K\|u\|_{\infty}+2 K d\right) K\left\|v_{1}-v_{2}\right\|_{\infty} .
\end{aligned}
$$

Thus $T_{n}$ is contractive if

$$
2|b| K\|g\|_{\infty}+2 K^{2}\|u\|_{\infty}|b|<1
$$

That is,

$$
0<d<\frac{1}{K}\left[\frac{1}{2 K|b|}-\|g\|_{\infty}\right]-\|u\|_{\infty} .
$$

Clearly, $T_{n}$ maps $C[0, d]$ onto itself if (19) is satisfied. Also, $T_{n}(0)=0$.

Suppose $v(t) \neq 0$ is a solution of (21), such that $v$ may lie outside of $[0, d]$. Then,

$$
\begin{aligned}
&\left(\chi_{n} v\right)(t)=\chi_{n} b\left[2 g(t) \int_{0}^{t} k(t, s) v(s) d s\right.+2 \int_{0}^{t} k(t, s) u(s) d s \cdot \int_{0}^{t} k(t, s) v(s) d s \\
&\left.\quad+\left(\int_{0}^{t} k(t, s) v(s) d s\right)^{2}\right] \\
&=b\left[2 g(t) \chi_{n}(t) \int_{0}^{t} k(t, s) \chi_{n}(s) v(s) d s\right. \\
& \quad+2 \int_{0}^{t} k(t, s) u(s) d s \chi_{n}(t) \\
& \quad \times \int_{0}^{t} k(t, s) \chi_{n}(s) v(s) d s \\
&\left.\quad+\left(\chi_{n}(t) \int_{0}^{t} k(t, s) \chi_{n}(s) v(s) d s\right)^{2}\right], \\
&=T_{n}\left(\chi_{n} v\right)(t),
\end{aligned}
$$

which shows that $\chi_{n} v$ is a fixed point of $T_{n}$ for all $n$. Since $\chi_{n} y \rightarrow 0$ in $C[0,1]$ as $A_{n} \rightarrow 0$, and for $v \neq 0$, we can select $\chi_{n} v \in[0, d]$. But this is impossible since 0 is the only solution in $[0, d]$. Therefore the solution $u$ of $(18)$ is unique in $C[0, d]$ if $d>0$ exists that satisfies (19).

Theorem 2. There exists a solution $u$ of $(1)$, where $u \in C[0, d]$ provided that

$$
\begin{gathered}
N_{b} \sum_{j=1}^{r} j\left|b_{j}\right|\left(\left\|g_{j}\right\|_{\infty}+K_{j} d\right)^{j-1} K_{j}<1, \\
\sum_{j=1}^{r}\left|b_{j}\right|\left(\left\|g_{j}\right\|_{\infty}+K_{j} d\right)<d,
\end{gathered}
$$

where $N_{b}$ is the number of nonzero $b_{j}$.
Proof. Let $T^{\prime} v(t)=\sum_{j=1}^{r} b_{j}\left(g_{j}(t)+\int_{0}^{t} k_{j}(t, s) v(s) d s\right)^{j}$ and $v_{1}, v_{2} \in[0, d]$ for a suitable $d$, and consider

$$
\begin{aligned}
& T^{\prime} v_{2}(t)-T^{\prime} v_{1}(t) \\
& =\sum_{j=1}^{r} b_{j}\left[\left(g_{j}(t)+\int_{0}^{t} k_{j}(t, s) v_{2}(s) d s\right)^{j}\right. \\
& \left.-\left(g_{j}(t)+\int_{0}^{t} k_{j}(t, s) v_{1}(s) d s\right)^{j}\right] \\
& =\sum_{j=1}^{r} b_{j}\left[\left(g_{j}(t)+\int_{0}^{t} k_{j}(t, s) v_{2}(s) d s-g_{j}(t)\right.\right. \\
& \left.-\int_{0}^{t} k_{j}(t, s) v_{1}(s) d s\right) \\
& \cdot \sum_{i=0}^{j-1}\left(g_{j}(t)+\int_{0}^{t} k_{j}(t, s) v_{2}(s)^{j} d s\right) \\
& \left.\cdot\left(g_{j}(t)+\int_{0}^{t} k_{j}(t, s) v_{1}(s)^{j} d s\right)^{j-1-i}\right] \\
& \stackrel{\text { def }}{=} \sum_{j=1}^{r} b_{j} F_{j}\left(t, v_{1}, v_{2}\right) \int_{0}^{t} k_{j}(t, s)\left(v_{2}(s)-v_{1}(s)\right) d s .
\end{aligned}
$$

So

$$
\begin{gathered}
\left\|T^{\prime} v_{2}-T^{\prime} v_{1}\right\|_{\infty} \\
\leq N_{b} \sum_{j=1}^{r} b_{j} \sup F_{j}\left(t, v_{1}, v_{2}\right) \cdot K_{j}\left\|v_{2}-v_{1}\right\|_{\infty} ; \\
\left\|F_{j}\right\|_{\infty} \leq j\left(\left\|g_{j}\right\|_{\infty}+K_{j} d\right)^{j-1}
\end{gathered}
$$

therefore

$$
\left\|T^{\prime} v_{2}-T^{\prime} v_{1}\right\|_{\infty} \leq N_{b} \sum_{j=1}^{r} j b_{j}\left(\left\|g_{j}\right\|_{\infty}+K_{j} d\right)^{j-1} K_{j}\left\|v_{2}-v_{1}\right\|_{\infty} .
$$

Consequently $T^{\prime}$ is a contraction mapping if

$$
N_{b} \sum_{j=1}^{r} j\left|b_{j}\right|\left(\left\|g_{j}\right\|_{\infty}+K_{j} d\right)^{j-1} K_{j}<1
$$
that

We need to show that $T^{\prime}: C[0, d] \rightarrow C[0, d]$. Observe

$$
\left\|\left(g_{j}(t)+\int_{0}^{t} k_{j}(t, s) v(s) d s\right)^{j}\right\|_{\infty} \leq\left(\left\|g_{j}\right\|_{\infty}+K_{j}\|v\|_{\infty}\right)^{j} .
$$


Therefore

$$
\begin{aligned}
\left\|T^{\prime} v\right\|_{\infty} & \leq \sum_{j=1}^{r}\left|b_{j}\right|\left(\left\|g_{j}\right\|_{\infty}+K_{j}\|v\|_{\infty}\right)^{j} \\
& \leq \sum_{j=1}^{r}\left|b_{j}\right|\left(\left\|g_{j}\right\|_{\infty}+K_{j} d\right)^{j}
\end{aligned}
$$

thus $T^{\prime}: C[0, d] \rightarrow C[0, d]$ if

$$
\sum_{j=1}^{r}\left|b_{j}\right|\left(\left\|g_{j}\right\|_{\infty}+K_{j} d\right)^{j}<d .
$$

Hence the map $T^{\prime}$ is a contraction and maps $[0, d]$ into itself provided (30) is satisfied.

Corollary 3. There exists a solution $u$ to the integral equation

$$
u(t)=b\left(g(t)+\int_{0}^{t} k(t, s) u(s) d s\right)^{2},
$$

where $u \in C[0, d]$ with

$$
0<d<\frac{1}{K}\left[\frac{1}{2|b| K}-\|g\|_{\infty}\right],
$$

if

$$
\|g\|_{\infty}<\frac{1}{4 K|b|}
$$

Proof. From Theorem 2 we get sufficient conditions for the existence of a solution

$$
\begin{gathered}
2 K|b|\left(\|g\|_{\infty}+K d\right)<1, \\
|b|\left(\|g\|_{\infty}+K d\right)^{2}<d .
\end{gathered}
$$

Inequality (41) is solved by any $d<\bar{d}$, where

$$
\bar{d}=\frac{1}{K}\left[\frac{1}{2|b| K}-\|g\|_{\infty}\right],
$$

and inequality (42) is equivalent to

$$
|b| K^{2} d^{2}+\left(2 K|b|\|g\|_{\infty}-1\right) d+|b|\|g\|_{\infty}^{2}<0 .
$$

This is satisfied by $d \in\left(d_{-}, d_{+}\right)$, where

$$
d_{ \pm}=\frac{1-2 K|b|\|g\|_{\infty} \pm \sqrt{1-4 K|b|\|g\|_{\infty}}}{2|b| K^{2}} .
$$

If the regularity condition

$$
1-4 K|b|\|g\|_{\infty}>0
$$

is satisfied, $d_{+}$and $d_{-}$are real and positive. Furthermore,

$$
\bar{d}=\frac{d_{-}+d_{+}}{2},
$$

so that (46) ensures $d \in\left(d_{-}, \bar{d}\right)$ satisfies both inequalities (41) and (42) in Theorem 2.

\section{Numerical Computations}

In our work we consider examples of (1) when $r=2$. We use (6) to approximate the solutions considering two special cases: $c_{1}=1 / 2$ (implicit midpoint method) and $c_{1}=1$ (implicit Euler method). We also use the repeated trapezoidal and repeated Simpson's rule. Since the methods are implicit we perform an iterative procedure at each step implementing a tolerance of $10^{-4}$. For each method we used three different values of $h: h=0.01, h=0.005$, and $h=0.0025$.

\subsection{Example 1. Consider the nonlinear VIE}

$$
u(t)=2\left(1+\int_{0}^{t}(t-s) u(s) d s\right)^{2} \quad 0 \leq t \leq 1,
$$

which arises from a nonlinear differential equation in [15] where $b_{1}=0$ and $b_{2}=2$.

4.1.1. Using Implicit Euler Method. When $c_{1}=1$ and $t_{n, 1}=$ $t_{n}+h$, the collocation solution of (48) is given by

$$
U_{n, 1}=2\left(1+F_{n}\left(t_{n, 1}\right)+U_{n, 1} \frac{h^{2}}{2}\right)^{2},
$$

where

$$
F_{n}\left(t_{n, 1}\right)=h \sum_{i=0}^{n-1}\left(t_{n}-t_{i}+\frac{h}{2}\right) U_{i, 1} .
$$

Figure 1 shows the solution to (48) at $h=0.01, h=0.005$, and $h=0.0025$.

4.1.2. Using Implicit Midpoint Method. When $c_{1}=1 / 2$ and $t_{n, 1}=t_{n}+(h / 2)$, the collocation solution of (48) is given by

$$
U_{n, 1}=2\left(1+F_{n}\left(t_{n, 1}\right)+U_{n, 1} \frac{h^{2}}{8}\right)^{2},
$$

where

$$
F_{n}\left(t_{n, 1}\right)=h \sum_{i=0}^{n-1}\left(t_{n}-t_{i}\right) U_{i, 1}
$$

Figure 2 shows the solution to (48) at $h=0.01, h=0.005$, and $h=0.0025$.

4.1.3. Using the Iterated Collocation. For $c_{1}=1 / 2$ the iterated collocation solution of (48) is given as

$$
u^{I}\left(t_{n}\right)=2\left(1+h \sum_{i=0}^{n-1} \int_{0}^{1}\left(t_{n}-t_{i}-s h\right) d s U_{i 1}\right)^{2} .
$$

Integrate to obtain

$$
u^{I}\left(t_{n}\right)=2\left(1+h \sum_{i=0}^{n-1}\left(t_{n}-t_{i}-\frac{h}{2}\right) U_{i 1}\right)^{2} .
$$

The iterated collocation solution of (48) with three different values of $h$ is shown in Figure 3. 


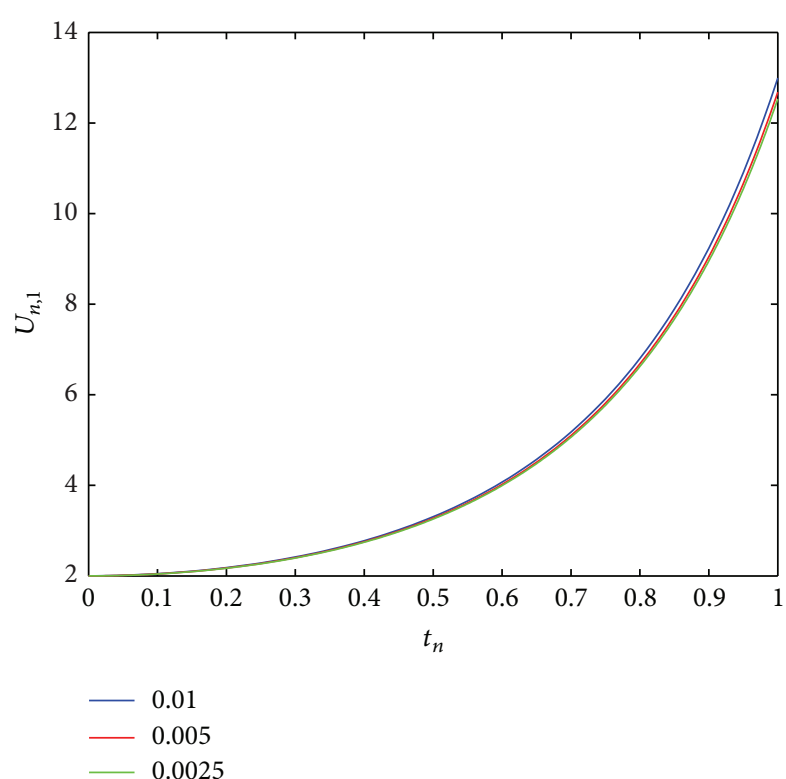

FIgURE 1: The collocation solution of (48) when $c_{1}=1$.

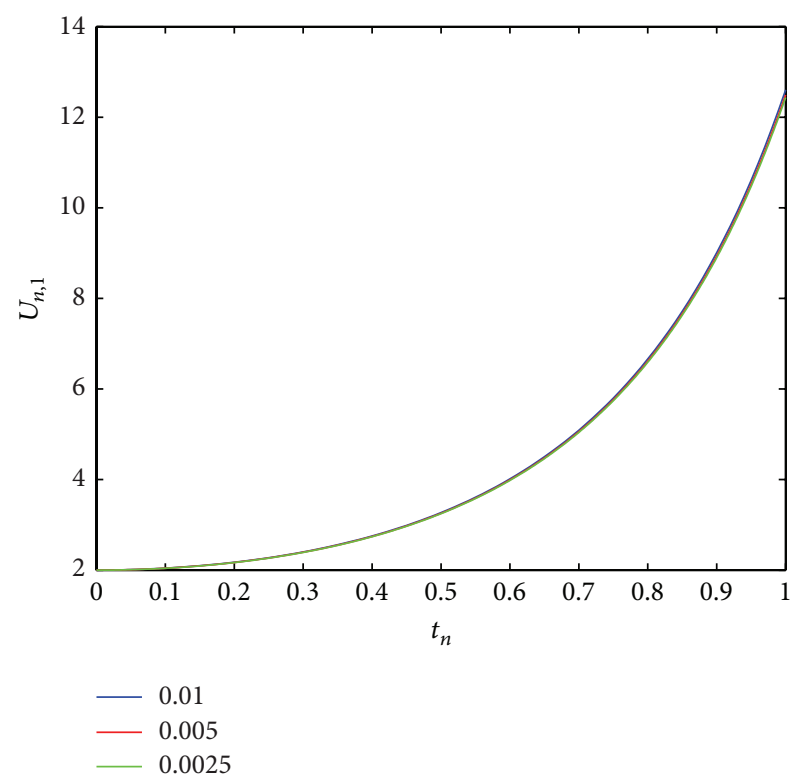

Figure 2: The collocation solution of (48) when $c_{1}=1 / 2$.

4.1.4. Using Repeated Trapezoidal Rule. For the VIE $u(0)=2$ and

$$
u\left(t_{n}\right)=2\left(1+\frac{h}{2} t_{n} u(0)+h \sum_{i=1}^{n-1}\left(t_{n}-t_{n-1}\right) u_{n-1}\right)^{2}
$$

Figure 4 shows the solution to the VIE (48) for the three values of $h$ used.

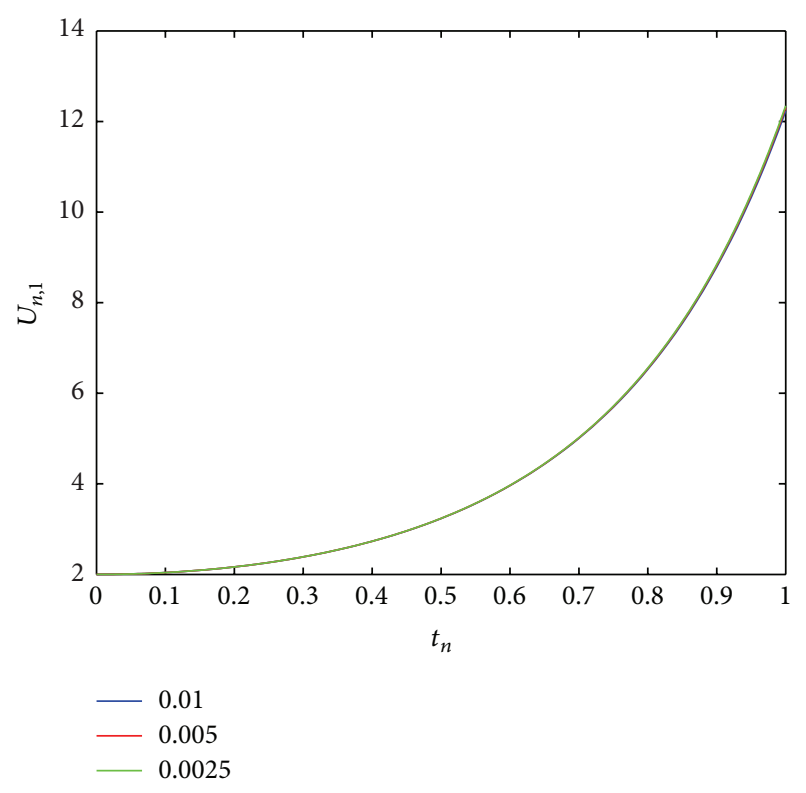

FIgURE 3: The iterated collocation solution of (48) when $c_{1}=1 / 2$.

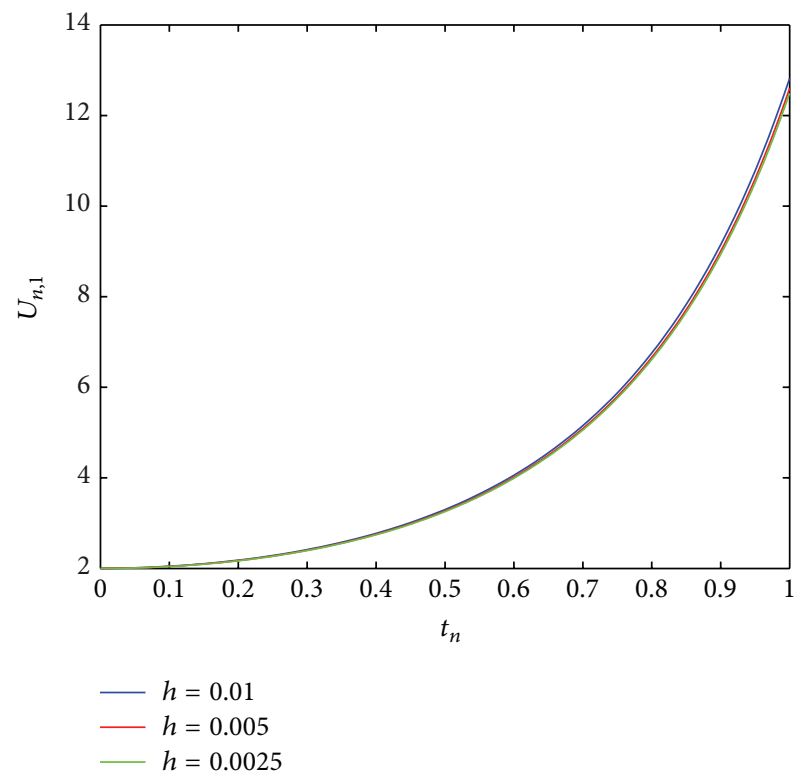

FIgURE 4: The solution of (48) by the repeated trapezoidal rule.

4.1.5. Using Repeated Simpson's Rule. When $t=0, u(0)=2$ for (48) and

$$
\begin{gathered}
u\left(t_{2 m}\right)=2\left[1+\frac{h}{3}\left(\left(3 t_{2 m}-2 t_{1}\right) u(0)\right.\right. \\
\left.+\left(2 t_{2 m}-2 t_{2 m-1}\right) u\left(t_{2 m}\right)\right) \\
\left.+\frac{2 h}{3} \sum_{l=0}^{m-1}\left(3 t_{2 m}-t_{2 l+1}-t_{l}-t_{2 l-1}\right) u\left(t_{2 l}\right)\right]^{2} .
\end{gathered}
$$

The solution to (48) using repeated Simpson's rule is shown in Figure 5. 
TABLE 1: Absolute errors in the solution of $(48)$ when $h=0.01$.

\begin{tabular}{lcccc}
\hline$t$ & $\begin{array}{c}\text { Implicit } \\
\text { euler }\end{array}$ & $\begin{array}{c}\text { Implicit } \\
\text { midpoint }\end{array}$ & $\begin{array}{c}\text { Repeated } \\
\text { trapezoidal }\end{array}$ & $\begin{array}{c}\text { Repeated } \\
\text { Simposon }\end{array}$ \\
\hline 0.1 & 0.0077 & 0.0038 & 0.0074 & - \\
0.2 & 0.0161 & 0.0078 & 0.0154 & 0.0001 \\
0.3 & 0.0266 & 0.0127 & 0.0252 & - \\
0.4 & 0.0406 & 0.0190 & 0.0377 & 0.0001 \\
0.5 & 0.0607 & 0.0275 & 0.0548 & 0.0005 \\
0.6 & 0.0907 & 0.0397 & 0.0180 & 0.0004 \\
0.7 & 0.1371 & 0.0576 & 0.1146 & 0.0007 \\
0.8 & 0.2115 & 0.0849 & 0.1689 & 0.0013 \\
0.9 & 0.3360 & 0.1280 & 0.2549 & 0.0023 \\
1 & 0.5530 & 0.1992 & 0.3966 & 0.0044 \\
\hline
\end{tabular}

TABLE 2: Absolute errors in the solution of (57) when $h=0.01$.

\begin{tabular}{lcccc}
\hline$t$ & $\begin{array}{c}\text { Implicit } \\
\text { euler }\end{array}$ & $\begin{array}{c}\text { Implicit } \\
\text { midpoint }\end{array}$ & $\begin{array}{c}\text { Repeated } \\
\text { trapezoidal }\end{array}$ & $\begin{array}{c}\text { Repeated } \\
\text { Simposon }\end{array}$ \\
\hline 0.1 & 0.0028 & 0.0014 & 0.0027 & - \\
0.2 & 0.0057 & 0.0028 & 0.0055 & - \\
0.3 & 0.0089 & 0.0043 & 0.0086 & - \\
0.4 & 0.0127 & 0.0061 & 0.0121 & 0.0001 \\
0.5 & 0.0171 & 0.0081 & 0.0162 & 0.0001 \\
0.6 & 0.0226 & 0.0105 & 0.0209 & 0.0001 \\
0.7 & 0.0295 & 0.0135 & 0.0239 & - \\
0.8 & 0.0385 & 0.0172 & 0.0342 & 0.0001 \\
0.9 & 0.0501 & 0.0219 & 0.0436 & 0.0001 \\
1.0 & 0.0659 & 0.0279 & 0.0553 & 0.0002 \\
\hline
\end{tabular}

Table 1 shows the errors in the solution of the integral equation (48) for the largest value of $h$ used.

\subsection{Example 2. Consider}

$$
\begin{aligned}
u(t)= & \left(1+\int_{0}^{t}(t-s) u(s) d s\right) \\
& +\frac{1}{2}\left(1+\int_{0}^{t}(t-s) u(s) d s\right)^{2} \quad 0 \leq t \leq 1,
\end{aligned}
$$

where $b_{1}=1$ and $b_{2}=1 / 2$. The integral equation (57) arises from nonlinear differential equations that represent conservative systems (see [16]). We used the four methods to approximate the solution to this example and Example 3, and we present tables for the absolute errors in the solution. Table 2 shows the errors in the solution of (57) when $h=0.01$ :

\subsection{Example 3. Consider the integral equation}

$$
\begin{aligned}
u(t)= & 2\left(1+\int_{0}^{t}(t-s) u(s) d s\right) \\
& +\left(1+\int_{0}^{t}(t-s) u(s) d s\right)^{2} \quad 0 \leq t \leq 1,
\end{aligned}
$$

TABLE 3: Absolute errors in the solution of (58) when $h=0.01$.

\begin{tabular}{lcccc}
\hline$t$ & $\begin{array}{c}\text { Implicit } \\
\text { euler }\end{array}$ & $\begin{array}{c}\text { Implicit } \\
\text { midpoint }\end{array}$ & $\begin{array}{c}\text { Repeated } \\
\text { trapezoidal }\end{array}$ & $\begin{array}{c}\text { Repeated } \\
\text { Simposon }\end{array}$ \\
\hline 0.1 & 0.0116 & 0.0057 & 0.0110 & - \\
0.2 & 0.0239 & 0.0116 & 0.0229 & 0.0001 \\
0.3 & 0.0389 & 0.0187 & 0.0369 & - \\
0.4 & 0.0586 & 0.0274 & 0.0543 & 0.0002 \\
0.5 & 0.0857 & 0.0390 & 0.0774 & 0.0003 \\
0.6 & 0.1247 & 0.0549 & 0.1089 & 0.0005 \\
0.7 & 0.1829 & 0.0773 & 0.1537 & 0.0009 \\
0.8 & 0.2727 & 0.1104 & 0.2196 & 0.0016 \\
0.9 & 0.4163 & 0.1607 & 0.3196 & 0.0028 \\
1.0 & 0.6541 & 0.2399 & 0.4771 & 0.0049 \\
\hline
\end{tabular}

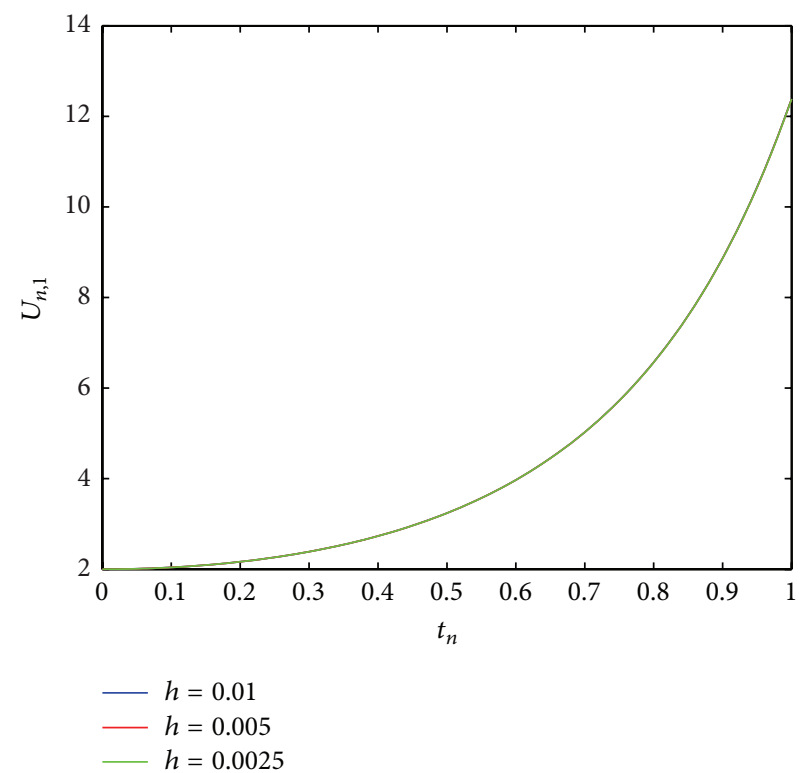

Figure 5: The solution of (48) by the repeated Simpson's rule.

where $b_{1}=2$ and $b_{2}=1$. The nonlinear VIE arises from a nonlinear differential equation in [17]. Shown in Table 3 are the errors in the solution of (58) when $h=0.01$.

\section{Discussion}

We approximated the solutions to Examples 1-3 using the implicit Euler method, implicit midpoint method, and repeated trapezoidal and repeated Simpson's rule using various values of the stepsize. At $h=0.001$ and below we obtained a similar solution from all the methods used; hence we take that as our "exact" solution. Therefore, for sufficiently small $h$ we get a good accuracy of the numerical solutions. When the stepsize is greater than 0.001 we obtained different numerical solutions from each of the four methods. We use the "exact" solution and absolute error to study the performance of each method when the stepsize is increased.

Tables 1-3 show the absolute errors in the solutions when $h=0.01$. From these tables we observe that the 
repeated Simpson's rule performs better followed by the implicit midpoint method then the repeated trapezoidal rule. Among the four methods used, the implicit Euler method gives a larger error as $h$ is increased. We then found an iterated collocation solution for the implicit midpoint method and the accuracy of the method improved as shown in Figure 3. According to our numerical results, we conclude that the repeated Simpson's rule performs well since it gives better solutions when a reasonably large value of the stepsize is used. These observations are consistent for all three examples used.

\section{Conflict of Interests}

The authors declare that there is no conflict of interests regarding the publication of this paper.

\section{References}

[1] D. Saveljeva, "Quadratic and cubic spline collocation for Volterra integral equations," 2006, http://dspace.utlib.ee/dspace/ handle/10062/1163.

[2] B. G. Sloss and W. F. Blyth, "Corrington's Walsh function method applied to a nonlinear integral equation," Journal of Integral Equations and Applications, vol. 6, no. 2, pp. 239-256, 1994.

[3] H. Brunner, "Iterated collocation methods for Volterra integral equations with delay arguments," Mathematics of Computation, vol. 62, no. 206, pp. 581-599, 1994.

[4] J. G. Blom and H. Brunner, "The numerical solution of nonlinear Volterra integral equations of the second kind by collocation and iterated collocation methods," Society for Industrial and Applied Mathematics. Journal on Scientific and Statistical Computing, vol. 8, no. 5, pp. 806-830, 1987.

[5] T. Diogo, "Collocation and iterated collocation methods for a class of weakly singular Volterra integral equations," Journal of Computational and Applied Mathematics, vol. 229, no. 2, pp. 363-372, 2009.

[6] T. Diogo and P. Lima, "Collocation solutions of weakly singular Volterra integral equation," Matemática Aplicada e Computacional, vol. 8, pp. 229-238, 2007.

[7] V. Horvat, "On collocation methods for Volterra integral equations with delay arguments," Mathematical Communications, vol. 4, no. 1, pp. 93-109, 1999.

[8] R. Benitez and V. J. Bolos, "Blow-up collocation solutions of some Volterra integral equations," 2011, http://arxiv.org/abs/1112 .4658 .

[9] M. Aigo, "On the numerical approximation of Volterra integral equations of the second kind using quadrature rules," International Journal of Advanced Scientific and Technological Research, vol. 1, pp. 558-564, 2013.

[10] R. Katani and S. Shahmorad, "Block by block method for the systems of nonlinear Volterra integral equations," Applied Mathematical Modelling, vol. 34, no. 2, pp. 400-406, 2010.

[11] F. Mirzaee, "A computational method for solving linear Volterra integral equations," Applied Mathematical Sciences, vol. 6, no. 17-20, pp. 807-814, 2012.

[12] J. Saberi-Nadjafi and M. Heidari, "A quadrature method with variable step for solving linear Volterra integral equations of the second kind," Applied Mathematics and Computation, vol. 188, no. 1, pp. 549-554, 2007.
[13] H. Brunner, Collocation Methods For Volterra Integral And Related Functional Differential Equations, Cambridge University Press, Cambridge, Mass, 2004.

[14] H. Brunner, "Iterated collocation methods and their discretizations for Volterra integral equations," SIAM Journal on Numerical Analysis, vol. 21, no. 6, pp. 1132-1145, 1984.

[15] M. S. Corrington, "Solution of differential and integral equations with walsh functions," IEEE Trans Circuit Theory, vol. 20, no. 5, pp. 470-476, 1973.

[16] R. H. Rand, Lecture notes on nonlinear vibrations, 2003, http://www.math.cornell.edu/ rand/randdocs/nlvibe52.pdf.

[17] D. G. Zill, W. S. Wright, and M. R. Cullen, Differential Equations with Boundary Value Problems, Richard Stratton, 2012. 


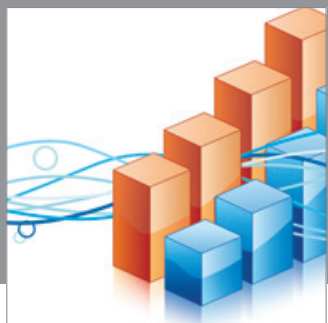

Advances in

Operations Research

mansans

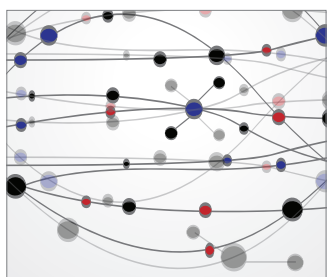

The Scientific World Journal
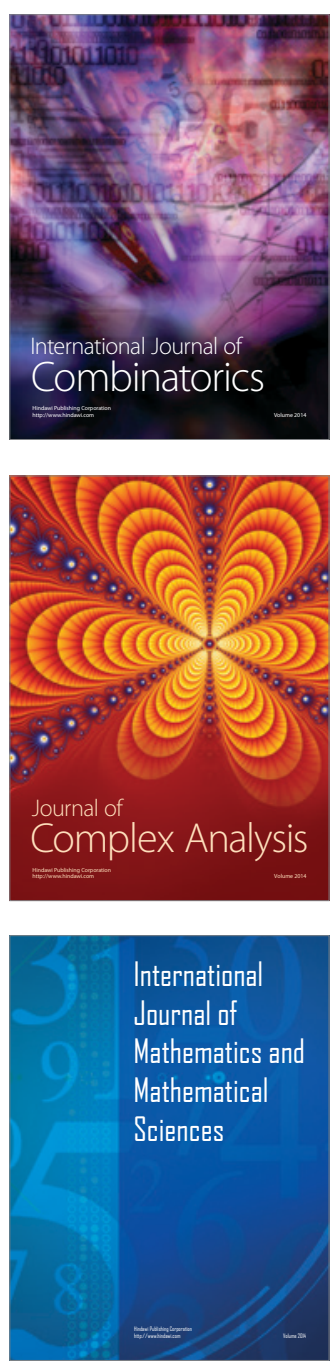
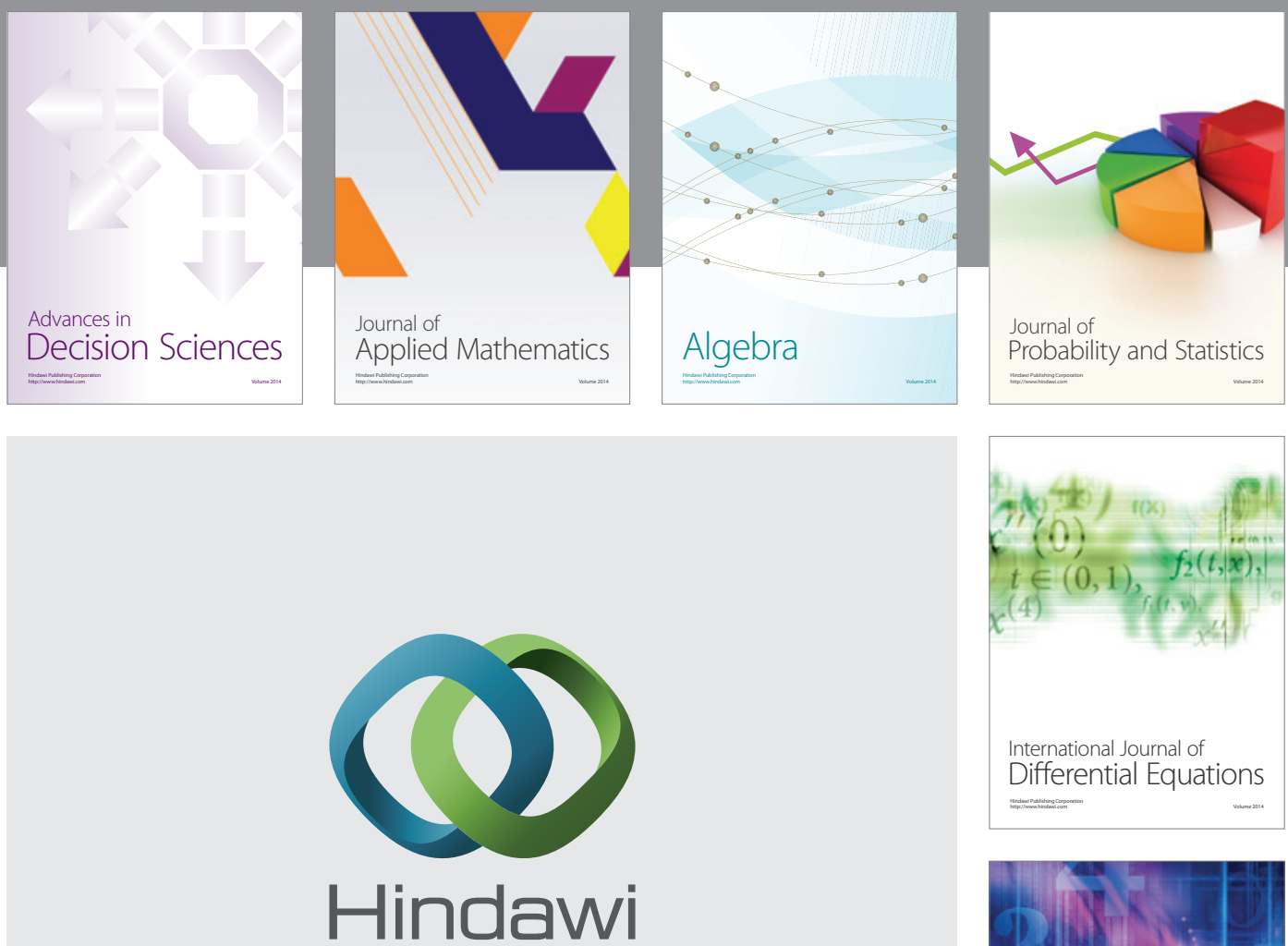

Submit your manuscripts at http://www.hindawi.com
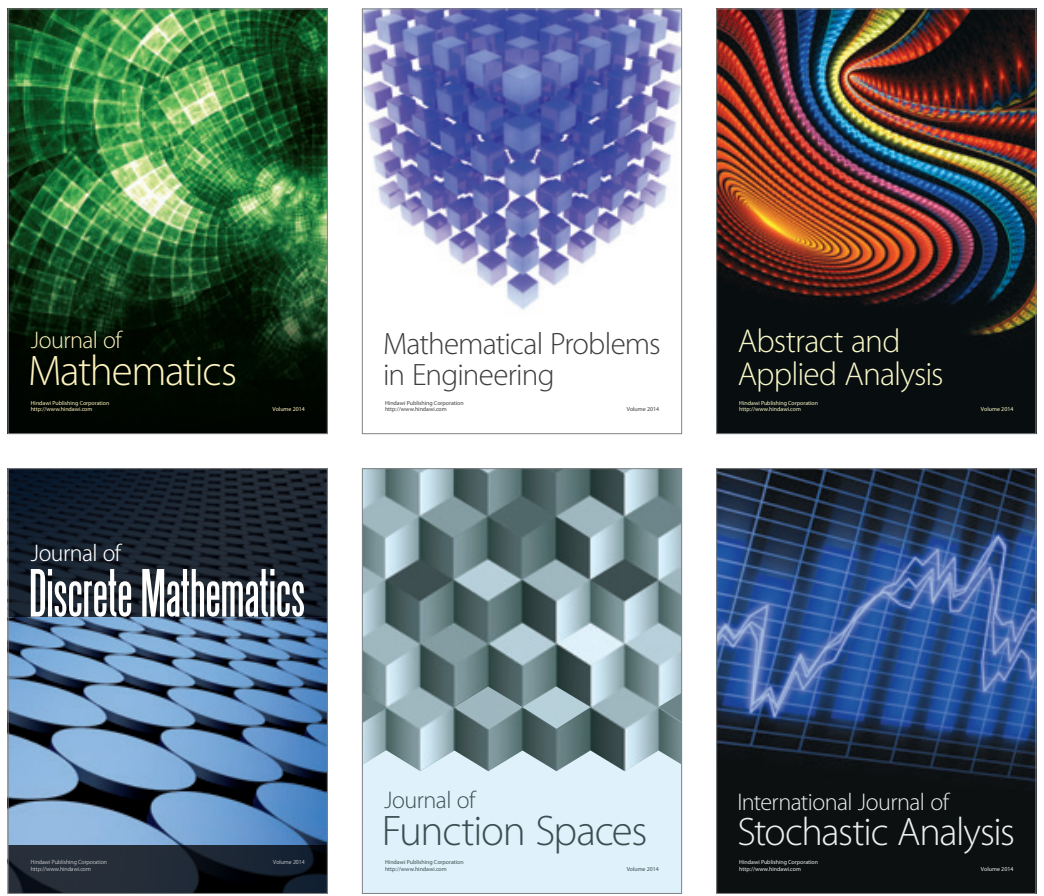

Journal of

Function Spaces

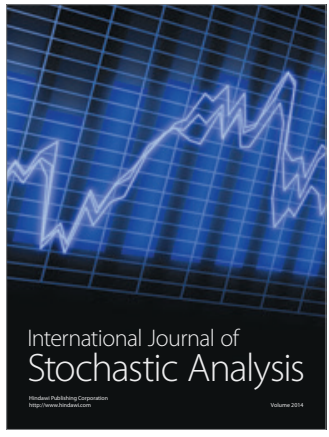

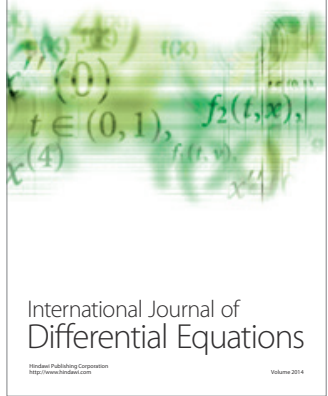
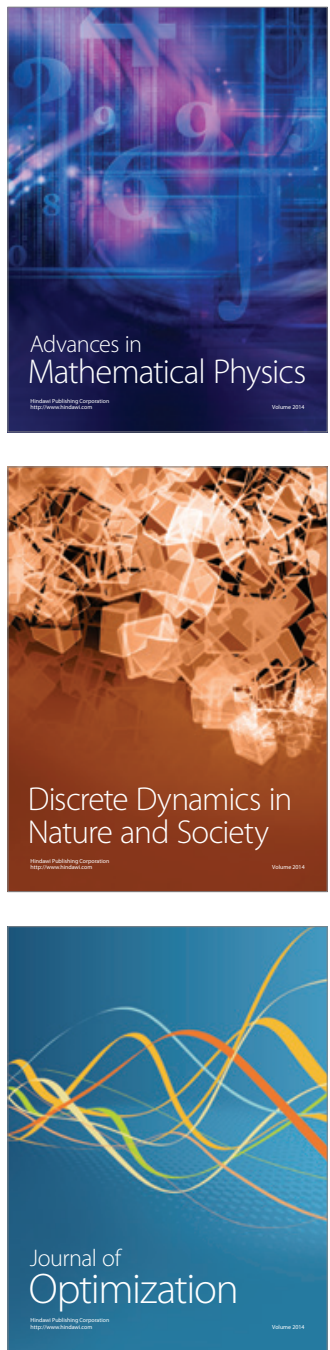